Article

\title{
Terrestrial Condition Assessment for National Forests of the USDA Forest Service in the Continental US
}

\author{
David Cleland ${ }^{1}$, Keith Reynolds ${ }^{2, *}$ (D), Robert Vaughan ${ }^{3}$, Barbara Schrader ${ }^{4}$, Harbin Li $^{5}$ and \\ Larry Laing 5 \\ 1 USDA Forest Service, National Forest System, Rhinelander, WI 54501, USA; dcleland@fs.fed.us \\ 2 USDA Forest Service, Pacific Northwest Research Station, Corvallis, OR 97331, USA \\ 3 Redcastle Resources, Inc., Salt Lake City, UT 84103, USA; robertvaughan@fs.fed.us \\ 4 USDA Forest Service, Alaska Region, Juneau, AK 99801, USA; bschrader@fs.fed.us \\ 5 USDA Forest Service, National Forest System, Washington, DC 20250, USA; hli@fs.fed.us (H.L.); \\ larrylaing@fs.fed.us (L.L.) \\ * Correspondence: kreynolds@fs.fed.us; Tel.: +1-541-750-7434
}

Received: 29 September 2017; Accepted: 18 November 2017; Published: 22 November 2017

\begin{abstract}
The terrestrial condition assessment (TCA) evaluates effects of uncharacteristic stressors and disturbance agents on land-type associations (LTAs) to identify restoration opportunities on national forest system (NFS) lands in the United States. A team of agency scientists and managers, representing a broad array of natural resource disciplines, developed a logic structure for the TCA to identify appropriate data sources to support analyses. Primary national data sources included observed insectand pathogen-induced mortality, key critical loads for soil and the atmosphere, long term seasonal departures in temperature and precipitation, road densities, uncharacteristic wildfires, historical fire regime departure, wildfire potential, insect and pathogen risk, and vegetation departure from natural range of variability. The TCA was implemented with the ecosystem management decision support (EMDS) system, a spatial decision support system for landscape analysis and planning. EMDS uses logic models to interpret data, synthesizes information over successive layers of logic topics, and draws inferences about the ecological integrity of LTAs as an initial step to identifying high priority LTAs for landscape restoration on NFS lands. Results from the analysis showed that about 74 percent of NFS lands had moderate or better overall ecological integrity. Major impacts to ecological integrity included risk of mortality due to insects and disease, extent of current mortality, extent of areas with high and very high wildfire hazard potential, uncharacteristically severe wildfire, and elevated temperatures. In the discussion, we consider implications for agency performance reporting on restoration activities, and subsequent possible steps, including strategic and tactical planning for restoration. The objective of the paper is to describe the TCA framework with results from a national scale application on NFS lands.
\end{abstract}

Keywords: ecological integrity; stressors; disturbance agents; spatial decision support; restoration; assessment

\section{Introduction}

National forests and grasslands, under the management of the U.S. Department of Agriculture Forest Service (USFS), have been experiencing unprecedented impacts due to uncharacteristic stressors and disturbance agents over the past few decades. The U.S. burns twice as many acres as three decades ago [1], fire seasons on average have been extended by 78 days in the western United States [2], and the largest insect and disease infestation on record globally is occurring in the western United States and Canada [3]. Multiple stressors are responsible for these problems, in particular warming 
temperatures, over-stocking and altered fuel complexes in fire dependent ecosystems due to fire suppression, and invasive species.

The USFS has conducted restoration related activities for decades, however the need for reestablishing and retaining resilience of national forest system (NFS) lands to achieve sustainable management has never been greater. The imminent risk of insects and disease, uncharacteristically high rates of mortality that have already occurred, and the extensive areas with high or very high wildfire hazard potential are major concerns of the USFS. Deleterious effects of elevated temperature and reduced precipitation, particularly in the west, uncharacteristically severe or frequent wildfire, fragmentation of habitat due to roads, and the effects of air pollution or invasive species are also adversely impacting NFS lands.

As a consequence, the USFS has made restoration a major priority within the agency. Policy [4], collaborative landscape restoration projects, and on-the-ground activities have emerged in response to restoration needs, with 1.9 million ha treated for restoration needs in 2014 alone. The team conducting the terrestrial condition assessment (TCA) was commissioned to develop a comprehensive assessment of resource conditions and stressors that may warrant restoration consideration to assist in identifying terrestrial restoration opportunities and improve the agency's transparency and accountability for terrestrial restoration investments. The TCA was chartered by the sustainable land management board of directors, composed of Washington office leadership from NFS, research, and state and private forestry branches of the USFS.

The TCA was designed to complement the watershed condition framework (WCF), a national effort to evaluate the status of watersheds across all NFS lands [5]. The TCA and WCF share goals of assessing resource conditions, but the focus and approach differ. The WCF focuses on conditions and stressors affecting water quality and quantity, and aquatic organisms and their habitat, uses watersheds as analytical and reporting units, and is based primarily on expert opinion in a paneling process that scores indicators of the ecological integrity of watersheds. The TCA addresses terrestrial outcomes, uses landscape-scale analytical and reporting units, is data-driven with existing national data sets, and provides an assessment of ecological integrity based on data interpretation and analyses.

The TCA assesses conditions and processes affecting the ecological integrity of landscape ecosystems on NFS lands. The concept of ecological integrity has evolved over the years [6-9]. It is commonly accepted that an ecosystem has integrity when its dominant ecological characteristics (composition, structure, function) occur within their natural ranges of variation, and can withstand and recover from perturbations caused by natural environmental processes or human activities [9-11]. Thus, the key elements of ecological integrity should include intactness (in terms of natural ranges of variation of all key indicators), biodiversity and species viability, ecosystem structure, ecological processes, and stressors.

In North America, ecological integrity has been mapped across national parks in Canada by the Canadian park service [9]. The Canadian approach includes ecological, species diversity, and human development measures, organized into biodiversity, ecosystem processes, and stressor categories. The National Park Service and NatureServe have developed a preliminary ecological integrity assessment framework intended to introduce concepts and methods to managers and to highlight their potential use [12]. The system recommends use of NatureServe's ecological systems as a coarse filter of biodiversity, but also employs measures of vulnerable species assemblages and their habitats, and species-level measures of the vulnerability of individual plant and animal species. Threats and stressors including human development, resource extraction, roads, pollution, and climate change are included in the assessment. The TCA estimates the ecological integrity of landscape ecosystems by comparing current conditions and processes to reference conditions and processes, but also includes indicators of uncharacteristic biological and environmental stressors, including air pollution and road density.

The TCA is a mid-scale evaluation of conditions and stressors occurring across NFS lands, utilizing the landtype association tier of the national hierarchical framework of Ecological Units [13] as 
analysis units. Landtype associations represent the landscape-level units in the hierarchy, averaging 8000 hectares in size. An ultimate goal is to understand the resilience of landscape ecosystems to stressors, as well as the extent and magnitude of various stressors themselves. However, methods and data for quantifying resilience are lacking [14]. Given our present inability to measure ecological resilience, we use estimates of ecological integrity as a proxy and as a means of addressing escalating degradative ecological changes. The primary goals of the TCA are to assist land managers in identifying restoration needs at a national scale, and provide the tools necessary for regional and local applications including science delivery, data access, and guidance on analytical procedures. Secondary goals are to support restoration prioritization activities, and provide a baseline from which restoration and maintenance activities can be tracked and effects on ecological integrity documented. The objective of the paper is to describe the TCA framework with results from a national scale application on NFS lands.

\section{Materials and Methods}

A team of scientists and resource specialists from NFS, Research and Development, and State and Private Forestry branches of the USFS conceived and designed the TCA. The team addressed questions related to current restoration investments, resource conditions warranting investments, appropriate scale and units of analysis, selection of measureable indicators, data availability and acquisition, and computational methods.

\subsection{Study Area and Analysis Units}

The TCA included all administrative units (National Forests and National Grasslands) of the NFS of the USFS in the continental United States (Figure 1). The total land area of the NFS is distributed across 112 administrative units (labeled "Forests" in the figure), and covers approximately 86 million ha.

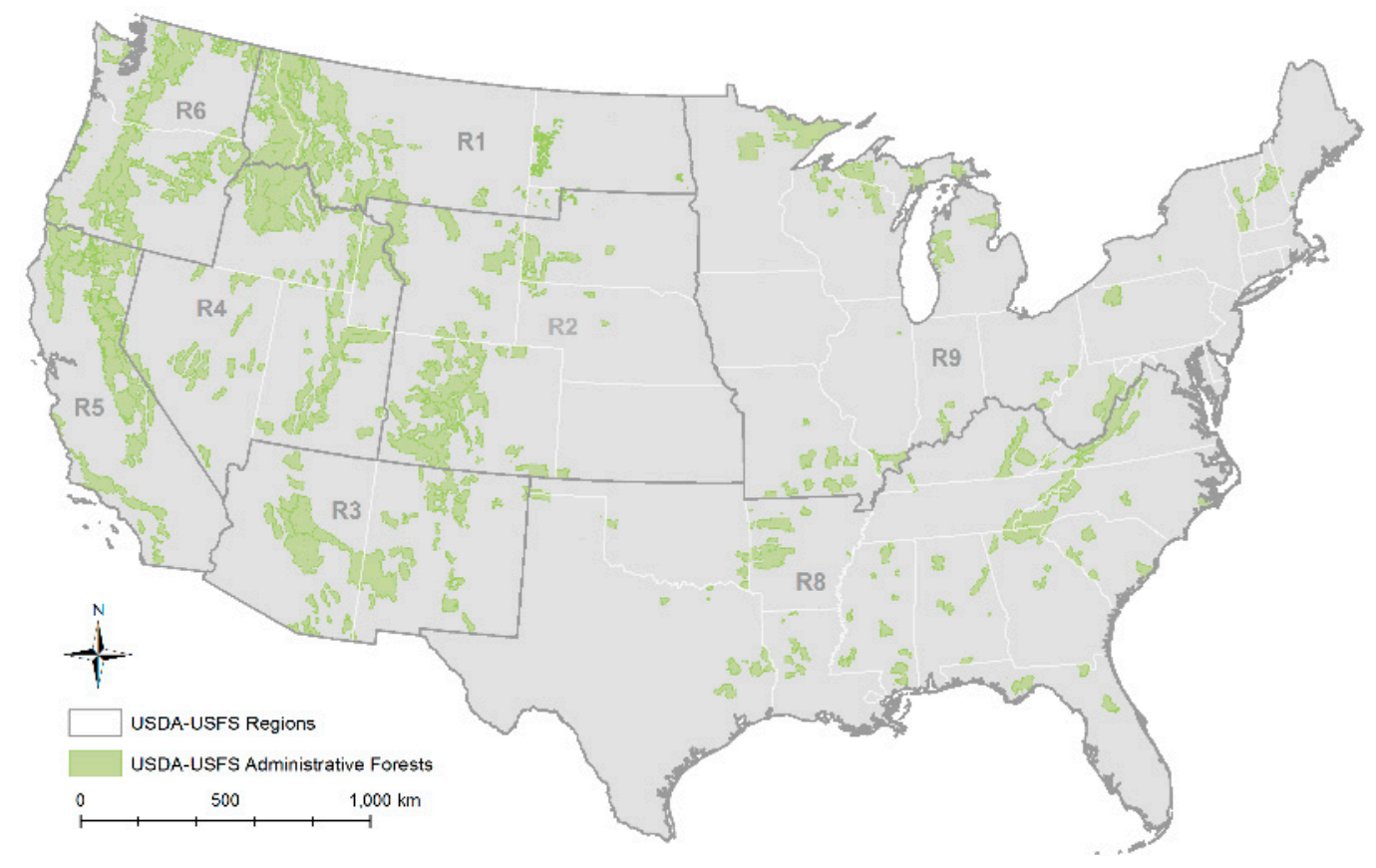

Figure 1. Study area of the Terrestrial Condition Assessment in the continental United States.

Landscape units used in TCA were a combination of landtype associations or generalizations of LANDFIRE's biophysical settings. LTAs are the landscape-level units in the national hierarchical framework of ecological units [13], and are based on patterns in surficial or bedrock geology, lithology, topography, soils and vegetation. LTAs were used in the analysis when these were available for an NFS region. Otherwise, the generalized biophysical settings were used as a close approximation to LTAs. 
The objective of using LTAs was to reduce the variability primarily in dominant vegetation as well as natural disturbance regimes. The study area included a total of 10,213 such landscape units. Hereafter, we refer to the analysis units as LTAs.

\subsection{Data Sources}

Data supporting the TCA were drawn from a variety of sources (Table 1). Estimates for each LTA were derived by zonal statistics using the appropriate input raster indicator dataset and LTA. This methodology was chosen specifically to reduce the overall variance within each estimate but also account for different resolution input indicator datasets. Detailed metadata on the metrics supporting each indicator are included in the supplementary materials .

Table 1. Data sources for metrics used in indicators of the Terrestrial Condition Assessment (TCA).

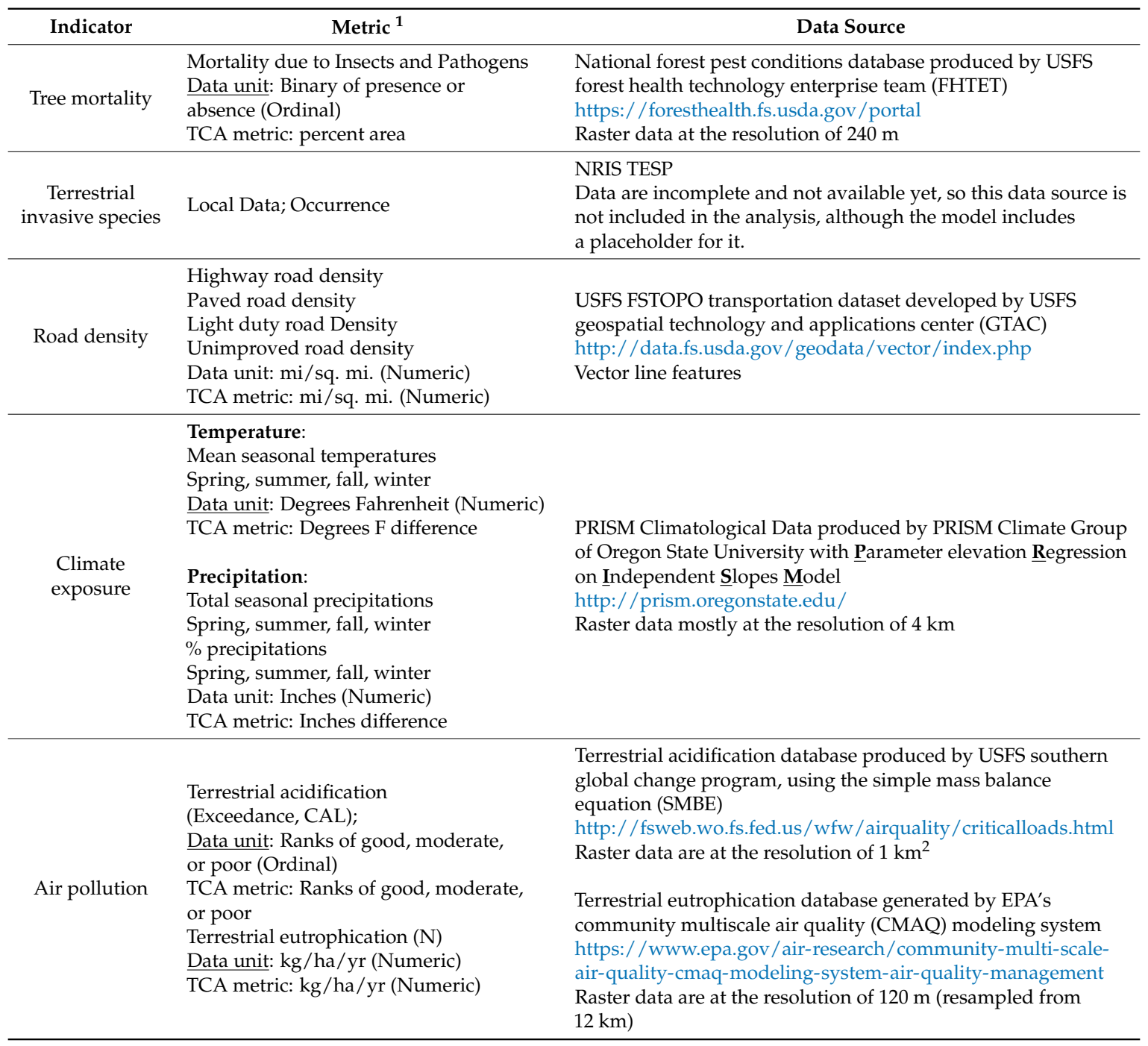


Table 1. Cont.

\begin{tabular}{|c|c|c|}
\hline Indicator & Metric $^{1}$ & Data Source \\
\hline $\begin{array}{l}\text { Catastrophic } \\
\text { disturbance }\end{array}$ & $\begin{array}{l}\text { Uncharacteristic fire severity } \\
\text { Uncharacteristic fire frequency } \\
\text { Data unit: Binary of uncharacteristic and } \\
\text { other (Ordinal) } \\
\text { TCA metric: Percent area }\end{array}$ & $\begin{array}{l}\text { Database of uncharacteristically severe wildfires derived from } \\
\text { (1) Monitoring trends in burn severity (MTBS) data by USGS } \\
\text { and USFS and (2) LANDFIRE data of percent low severity fire } \\
\text { and percent mixed-severity Fire } \\
\text { http:/ / mtbs.gov } \\
\text { https:/ / landfire.gov / fireregime.php } \\
\text { Raster data at the resolution of } 30 \mathrm{~m} \\
\text { Database of uncharacteristically frequent fire derived from } \\
\text { a combination of (1) MTBS as the current condition and (2) } \\
\text { Mean fire return interval (MFRI) of LANDFIRE as the } \\
\text { reference condition. }\end{array}$ \\
\hline $\begin{array}{l}\text { Wildfire } \\
\text { potential }\end{array}$ & $\begin{array}{l}\text { Uncharacteristic fuel buildup } \\
\text { Data unit: Binary of high risk or other } \\
\text { TCA metric: Percent area }\end{array}$ & $\begin{array}{l}\text { Wildfire hazard potential (WHP) database produced by USFS } \\
\text { Fire Modeling Institute } \\
\text { http:/ / www.firelab.org/project/ wildfire-hazard-potential } \\
\text { Raster data at the resolution of } 270 \mathrm{~m}\end{array}$ \\
\hline $\begin{array}{l}\text { Insect and } \\
\text { pathogen risk }\end{array}$ & $\begin{array}{l}\text { Potential uncharacteristic mortality } \\
\text { Data unit: Binary of presence or } \\
\text { absence (Ordinal) } \\
\text { TCA metric: Percent area }\end{array}$ & $\begin{array}{l}\text { National insect and disease risk map (NIDRM) produced by } \\
\text { USFS forest health protection (FHP) } \\
\text { http: / / www.fs.fed.us / foresthealth/technology/nidrm. } \\
\text { shtmlRaster data at the resolution of } 270 \mathrm{~m}\end{array}$ \\
\hline $\begin{array}{l}\text { Vegetation } \\
\text { departure }\end{array}$ & $\begin{array}{l}\text { Vegetation departure index } \\
\text { Data unit: } 0-100 \% \text { (Numeric) } \\
\text { TCA metric: Mean }\end{array}$ & $\begin{array}{l}\text { Vegetation departure index (VDEP) produced by LANDFIRE } \\
\text { http:/ / www.landfire.gov } \\
\text { Raster data at the resolution of } 30 \mathrm{~m}\end{array}$ \\
\hline $\begin{array}{l}\text { Ecological } \\
\text { process } \\
\text { departure }\end{array}$ & $\begin{array}{l}\text { Missed Fire Cycle } \\
\text { TCA metric: Mean }\end{array}$ & $\begin{array}{l}\text { Mean fire return interval (MFRI) produced by LANDFIRE } \\
\text { http://www.landfire.gov }\end{array}$ \\
\hline
\end{tabular}

\subsection{Overview of EMDS Framework}

EMDS is a spatially enabled decision-support framework for integrated landscape evaluation and planning [15]. We describe EMDS as a decision support framework because the data sources, scales of analysis, and models employed in EMDS applications are all user defined. As a result, the system has been applied to a wide variety of decision support problems since 1997 [16,17]. At version 5.5, the system provides decision support for landscape-level analyses through logic and decision engines integrated with the ArcGIS ${ }^{\circledR}$ 10.x geographic information system (GIS, Environmental Systems Research Institute, Redlands, CA, USA), as well as QGIS [18] and MapWindow [19]. The NetWeaver logic engine (Rules of Thumb, Inc., North East, PA) evaluates landscape data against a formal logic specification (e.g., a knowledge base in the strict sense) designed in NetWeaver Developer ${ }^{\circledR}$ [20], to derive logic-based interpretations of ecosystem conditions such as ecosystem integrity. EMDS 5.5 implements the decision engines of three decision support applications. Criterium DecisionPlus ${ }^{\circledR}$ (CDP, InfoHarvest, Seattle, WA, USA) implements the analytical hierarchy process (AHP) [21,22], and can be used for both strategic and tactical planning. GeNIe ${ }^{\circledR}$ (BayesFusion, LLC, Pittsburg, PA, USA) implements Bayesian networks and influence diagrams, while VisiRule ${ }^{\circledR}$ (Logic Programming Associates, Ltd, London, UK) implements Prolog-based decision trees. Both GeNIe and VisiRule are perhaps most applicable to tactical planning in the EMDS context, although strategic applications are also possible. The terms strategic and tactical planning have various interpretations, depending on context. In the particular context of spatial decision support, strategic planning in EMDS is concerned with which management units are the highest priority for management activities, whereas tactical planning is concerned with selecting the highest priority management actions in specific landscape features.

In the present study, our analysis is limited to logic-based processing to assess ecological integrity of LTAs. However, we have introduced the decision engines in this section because their functionality is pertinent to subsequent steps in the larger decision support process that is considered in the later Discussion section. 


\subsection{NetWeaver Logic Design for TCA}

NetWeaver models are implemented as a network of networks (Figure 2). For example, evaluation of the logic network, terrestrial condition, is directly dependent on the evaluation of the two networks, disturbance agents and vegetation condition, at the next lower level of the network outline. Conversely, we can describe the relation as disturbance agents and vegetation condition are logically antecedent to terrestrial condition. Similarly, biotic agents and abiotic agents are the direct logical antecedents of disturbance agents.

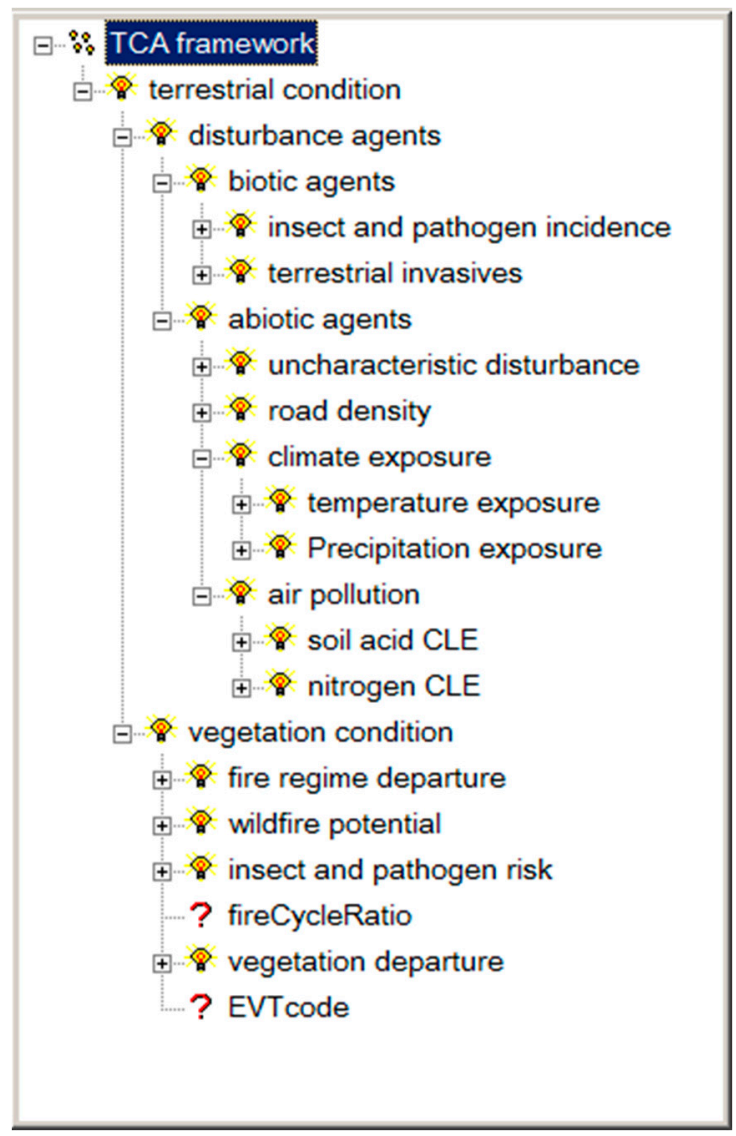

Figure 2. Outline of NetWeaver logic structure for the Terrestrial Condition Assessment. The top level, TCA framework, is simply a container for logic networks. Each item in the outline is a logic network, except fireCycleRatio and EVTcode, which are data inputs used to control the flow of logic processing under the network, vegetation condition. Networks listed under vegetation condition represent the latter's logical antecedents (e.g., the evaluation of vegetation conditions depends on fire regime departure, etc.). See the accompanying text for additional explanation of network concepts in NetWeaver.

Apart from its name, each logic network that makes up a logic model has four other important attributes. Each network:

1. Evaluates a proposition about the topic represented by the network, which is contained in a comment field;

2. Has a logical specification composed of its immediate logical antecedents and one or more logic operators that determine how the antecedents contribute to the proposition;

3. Has a measure of the strength of evidence for the proposition provided by its antecedents;

4. Has one or more documentation attributes that describe important aspects of the network (e.g., most networks have an explanation attribute at a minimum). 
In the interest of space, the TCA logic outline (Figure 2) is not shown fully expanded. In particular, the model includes additional levels of logic under the networks such as uncharacteristic disturbance, road density, and climate exposure. Comprehensive HTML documentation on the NetWeaver logic for TCA can be found in the supplementary materials section below.

As suggested by the phrase, "a network of networks", NetWeaver models are structurally recursive, such that higher level networks are composed of antecedent networks. This structural recursion terminates with elementary networks that evaluate data. Within each elementary network, data are interpreted with fuzzy logic by comparing observed data values to fuzzy membership functions that translate the observed value into a measure of the strength of evidence for the parent elementary network [20]. Metrics for strength of evidence are propagated upward through the logic structure. Within each network, the strength of evidence metrics contributed by the antecedent networks in the logic specification of their dependent network are logically synthesized by fuzzy logic operators such as AND, OR, and Union [20].

Threshold values presented in Table 2 were established based on a review of the literature, consultation with subject matter experts, and examination of data distributions to ensure model sensitivity. For example, thresholds for indicator 1, extent of insect and disease caused mortality in the past five years, are set at $5 \%$ for full evidence of high integrity and $25 \%$ for no evidence of high integrity. The 2013-2027 national insect and disease forest risk assessment [23] uses a natural annual background rate of $0.89 \%$ for evaluating mortality at a national scale. Based on this literature, the TCA evaluated mortality occurring within the past five years, and considered rates of $5 \%$ or less to be natural. The $25 \%$ or greater value represents systems that are experiencing mortality at five or more times the natural background rate, affecting ten percent of LTA's nationally. Values between $5 \%$ and $25 \%$ are ramped and evaluated continuously between these thresholds, such that $7 \%$ mortality is very close to full evidence and $23 \%$ very close to no evidence.

For readers who may not be familiar with fuzzy logic theory, here, we provide a brief comparison to probability theory, and related issues around confidence limits. Whereas probability theory is concerned with uncertainty in the sense of uncertainty about the likelihood of events, fuzzy logic is concerned with a fundamentally different concept of uncertainty, referred to as linguistic (or lexical) uncertainty [24-26], which originates in the imprecision of human thought and communication. For example, the concept of a warm day is linguistically imprecise (hence fuzzy). Fuzzy logic, or more generally fuzzy math and fuzzy set theory, is actually a precise mathematics for handling imprecise information [24-26]. Fuzzy membership functions, introduced above, are a way of expressing linguistic uncertainty in terms of set theory (e.g., to what degree is an observation a member of some fuzzy set?). The metric for strength of evidence, discussed in the context of NetWeaver, is simply another way of describing degree of set membership, and thus uncertainty. Finally, most readers will have had some training in probabilistic uncertainty, so there is an expectation that our results should include confidence limits on the fuzzy metrics presented in maps of the Results section. There are two compelling reasons why confidence limits are not treated in NetWeaver outputs in EMDS. First, conceptually, doing so would conflate two fundamentally different measures of uncertainty (e.g., probabilistic and linguistic). Second, as a practical matter, the computation of confidence intervals would require solving a convolution integral [27] for the roughly 40 inputs on each of about 10,000 observations, and this assumes that one has error estimates for each of the 400,000 observations, and that the computational algorithm could account for the nonlinearities intrinsic to the logic at runtime. This last reason is a compelling counterargument. 
Table 2. Indicators, metrics, and thresholds values used in the Terrestrial Condition Assessment.

\begin{tabular}{|c|c|c|c|c|c|}
\hline $\begin{array}{l}\text { Indicator } \\
\text { Number }\end{array}$ & TCA Indicator & Associated Metrics & $\begin{array}{l}\text { Threshold for } \\
\text { No Evidence } 1\end{array}$ & $\begin{array}{l}\text { Threshold for } \\
\text { Full Evidence }{ }^{2}\end{array}$ & Unit \\
\hline 1 & Tree mortality & $\begin{array}{l}\text { Mortality due to insects } \\
\text { and pathogens }\end{array}$ & 25.0 & 5.0 & $\begin{array}{c}\text { \% Land-type } \\
\text { associations (LTA) area }\end{array}$ \\
\hline \multirow{4}{*}{3} & \multirow{4}{*}{ Road density } & Highway & 0.3 & 0.1 & mile/square mile \\
\hline & & Paved roads & 0.3 & 0.1 & mile/square mile \\
\hline & & Light duty roads & 1.5 & 0.5 & mile/square mile \\
\hline & & Unimproved roads & 2.5 & 1.0 & mile/square mile \\
\hline \multirow{12}{*}{4} & \multirow{12}{*}{ Climate exposure } & Spring temperature & 2.0 & 0.0 & ${ }^{\circ} \mathrm{F}$ changed \\
\hline & & Summer temperature & 2.0 & 0.0 & ${ }^{\circ} \mathrm{F}$ changed \\
\hline & & Fall temperature & 2.0 & 0.0 & ${ }^{\circ} \mathrm{F}$ changed \\
\hline & & Winter temperature & 2.0 & 0.0 & ${ }^{\circ} \mathrm{F}$ changed \\
\hline & & Spring precipitation & -1.0 & 0.0 & inch changed \\
\hline & & Summer precipitation & -1.0 & 0.0 & inch changed \\
\hline & & Fall precipitation & -1.0 & 0.0 & inch changed \\
\hline & & Winter precipitation & -1.0 & 0.0 & inch changed \\
\hline & & Spring precipitation (\%) & -10.0 & 0.0 & $\%$ changed \\
\hline & & Summer precipitation (\%) & -10.0 & 0.0 & $\%$ changed \\
\hline & & Fall precipitation (\%) & -10.0 & 0.0 & $\%$ changed \\
\hline & & Winter precipitation $(\%)$ & -10.0 & 0.0 & $\%$ changed \\
\hline \multirow{2}{*}{5} & \multirow{2}{*}{ Air pollution } & Terrestrial acidification & poor & good & rank \\
\hline & & Terrestrial eutrophication (N) & 10.0 & 1.6 & $\mathrm{~kg} / \mathrm{ha} / \mathrm{yr}$ \\
\hline \multirow{2}{*}{6} & \multirow{2}{*}{$\begin{array}{l}\text { Catastrophic } \\
\text { disturbance }\end{array}$} & Uncharacteristic fire severity & 5.0 & 0.0 & $\%$ LTA area \\
\hline & & Uncharacteristic fire frequency & 1.0 & 1.5 & dimensionless \\
\hline 7 & Wildfire potential & Uncharacteristic fuel buildup & 66.0 & 20.0 & $\%$ LTA area \\
\hline 8 & $\begin{array}{l}\text { Insect and } \\
\text { pathogen risk }\end{array}$ & $\begin{array}{c}\text { Potential } \\
\text { uncharacteristic mortality }\end{array}$ & 50.0 & 10.0 & $\%$ LTA area \\
\hline 9 & $\begin{array}{l}\text { Vegetation } \\
\text { departure }\end{array}$ & Vegetation departure index & 67.0 & 43.0 & $\%$ area departed \\
\hline 10 & $\begin{array}{c}\text { Ecological } \\
\text { process departure }\end{array}$ & Missed fire cycle & 35.0 & 200.0 & year departed \\
\hline
\end{tabular}

${ }^{1}$ Value at which the fuzzy membership function interpreting the associated metric provides no evidence for a suitable condition; ${ }^{2}$ Value at which the fuzzy membership function interpreting the associated metric provides full evidence for a suitable condition.

\subsection{TCA Analysis in EMDS System}

The TCA analysis to assess the ecological integrity of LTAs on NFS lands was implemented in the ArcMap (ESRI) version of the EMDS system. All metrics needed for the assessment (Table 2) were initially obtained or developed as separate GIS layers. Zonal statistics procedures, available in ArcMap, were used to attribute each metric to the LTA polygons. The TCA analysis for the full set of 10,213 LTAs in the continental U.S. was performed with the NetWeaver model (Section 2.4). Within EMDS, the basic products of a NetWeaver analysis are maps displaying the strength of evidence associated with the proposition for each logic topic (Figure 2). In the case of indicators evaluated in terms of multiple metrics (Table 2), map products assessing strength of evidence also were produced for each individual metric. The final ArcMap document (e.g., mxd file), including all map products of the TCA, is available in the supplementary materials section. After completing the full national TCA assessment for the continental U.S., results were parsed to each NFS Region and National Forest for subsequent use by these units. Within the overall scheme of the TCA process, it was envisioned that Regions and Forests could modify data inputs and NetWeaver logic as needed to improve the relevance of analytical products at the latter smaller spatial extents. Customizing the TCA for other spatial extents is addressed further in the Discussion.

\section{Results}

At a national scale, $55 \%$ of national forests and grasslands are in very good or good condition, whereas $26 \%$ are in poor or very poor condition (Table 3, Figure 3). Overall TCA condition ratings are based on simultaneous consideration of nine indicators and the twenty six metrics used to characterize indicators (Table 2). The importance of indicators varies geographically, and interpretations 
of conditions leading to an overall landscape ecosystem rating need to be made at a local scale. However broad generalizations can be made. The very poorest conditions are principally due to high insect and disease risk, extensive mortality occurring within the past 5 years, and high and very high wildfire hazard potential (Figures 4-6). Effects of elevated temperature and reduced precipitation, uncharacteristically severe or frequent wildfire, and fragmentation of habitat due to roads are also strongly associated with very poor and poor conditions (Figures 7-10).

Table 3. Frequency and areal distributions of the LTAs among the five overall ecological integrity ratings at the national scale.

\begin{tabular}{cccc}
\hline Terrestrial Condition $^{\mathbf{1}}$ & Frequency & Hectares & Percent of National Forest System Lands \\
\hline Very Good & 1618 & $15,862,119$ & 18.41 \\
Good & 3962 & $31,896,498$ & 37.02 \\
Moderate & 1736 & $15,942,480$ & 18.50 \\
Poor & 1226 & $9,785,574$ & 11.36 \\
Very Poor & 1491 & $12,669,501$ & 14.71 \\
\hline
\end{tabular}

${ }^{1}$ Classes used for classification of terrestrial condition in this table, and subsequent tables and figures, represent equal intervals on the NetWeaver scale for strength of evidence, with very good condition being $\geq 0.60$, good condition being $<0.60$ and $\geq 0.20$, etc.

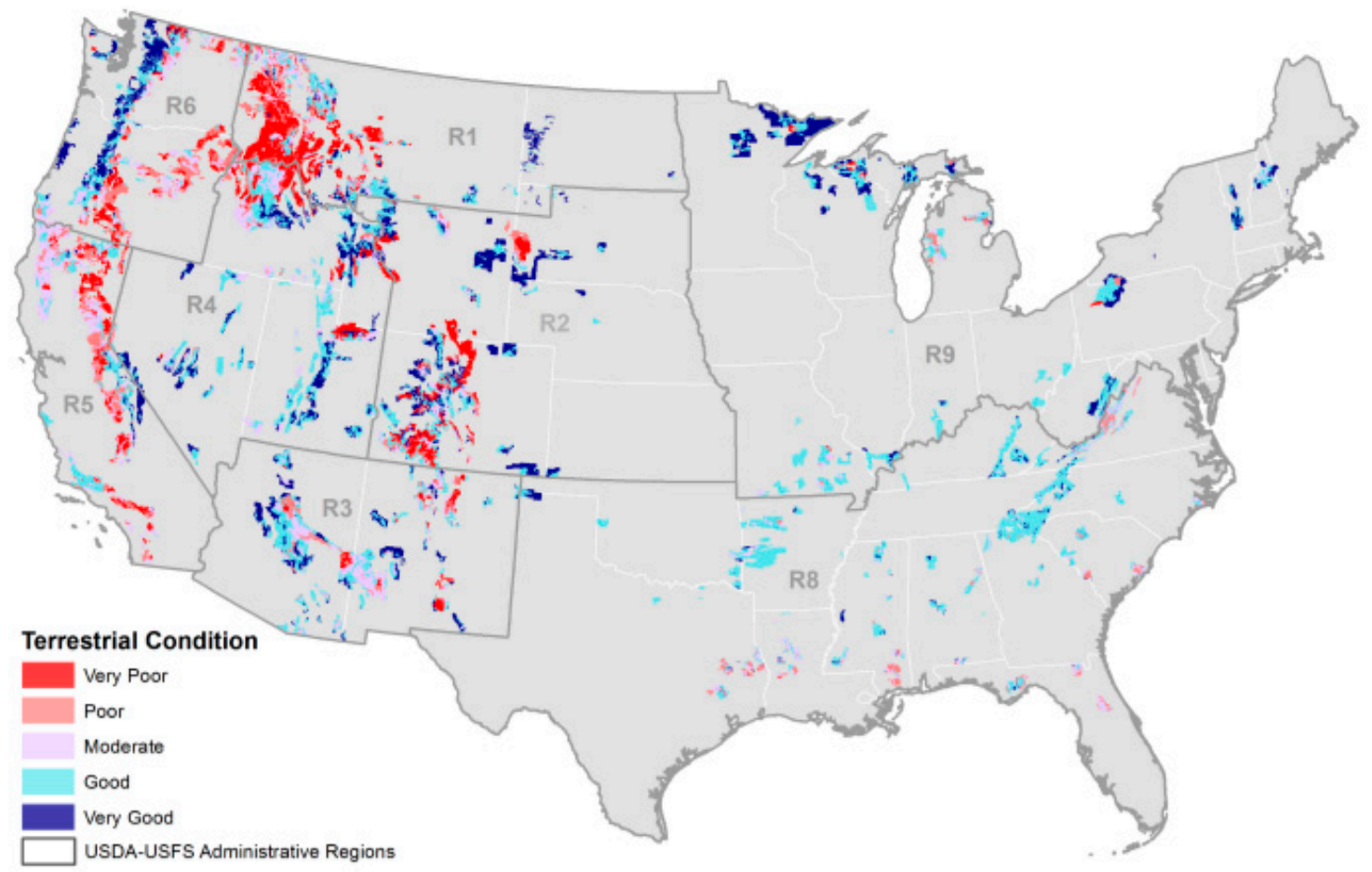

Figure 3. Overall ratings of the LTAs from the Terrestrial Condition Assessment on USDA Forest Service administrative lands. 


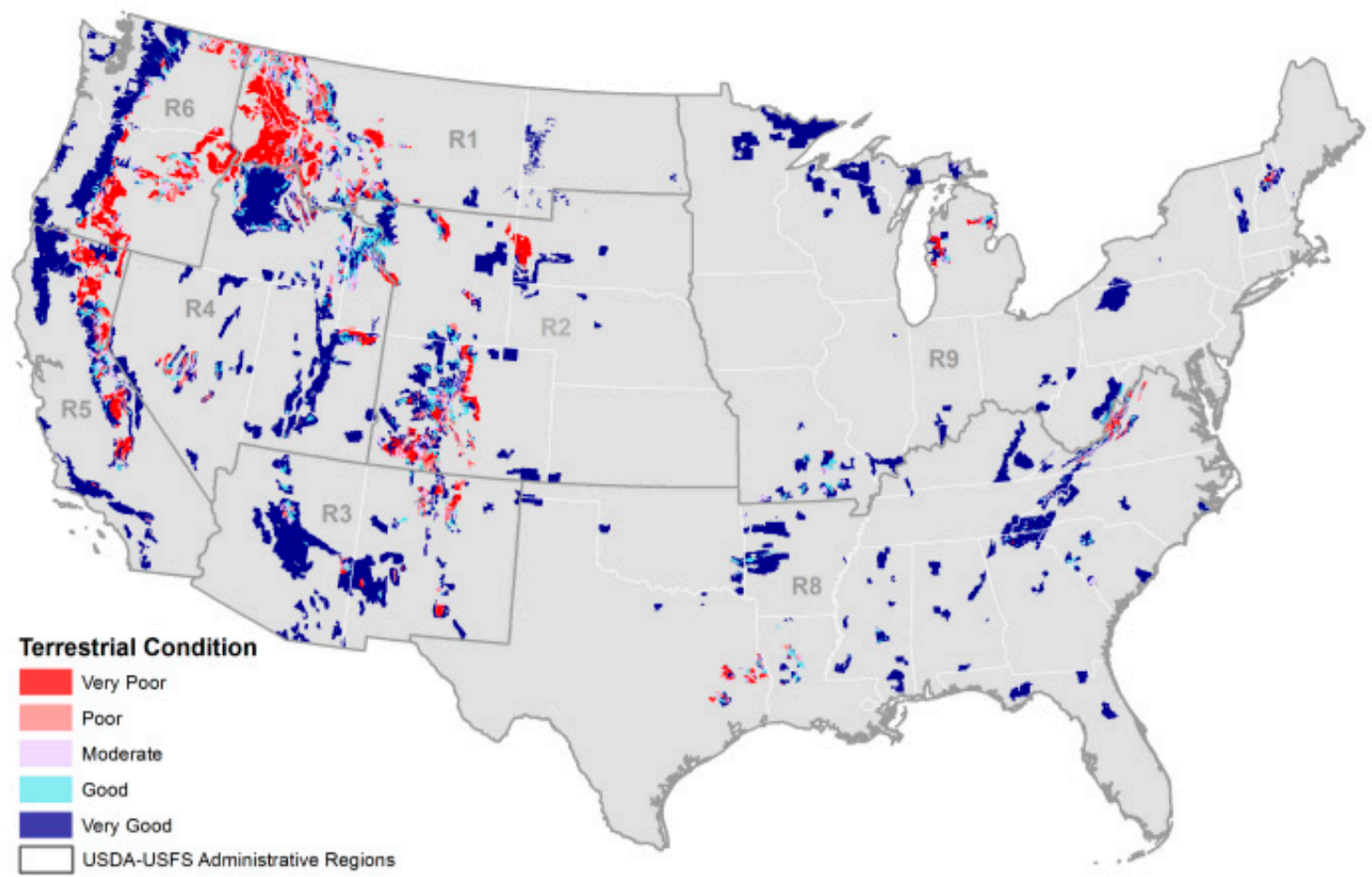

Figure 4. Ratings of the insect and disease risk metric of the LTAs from the Terrestrial Condition Assessment on USDA Forest Service lands.

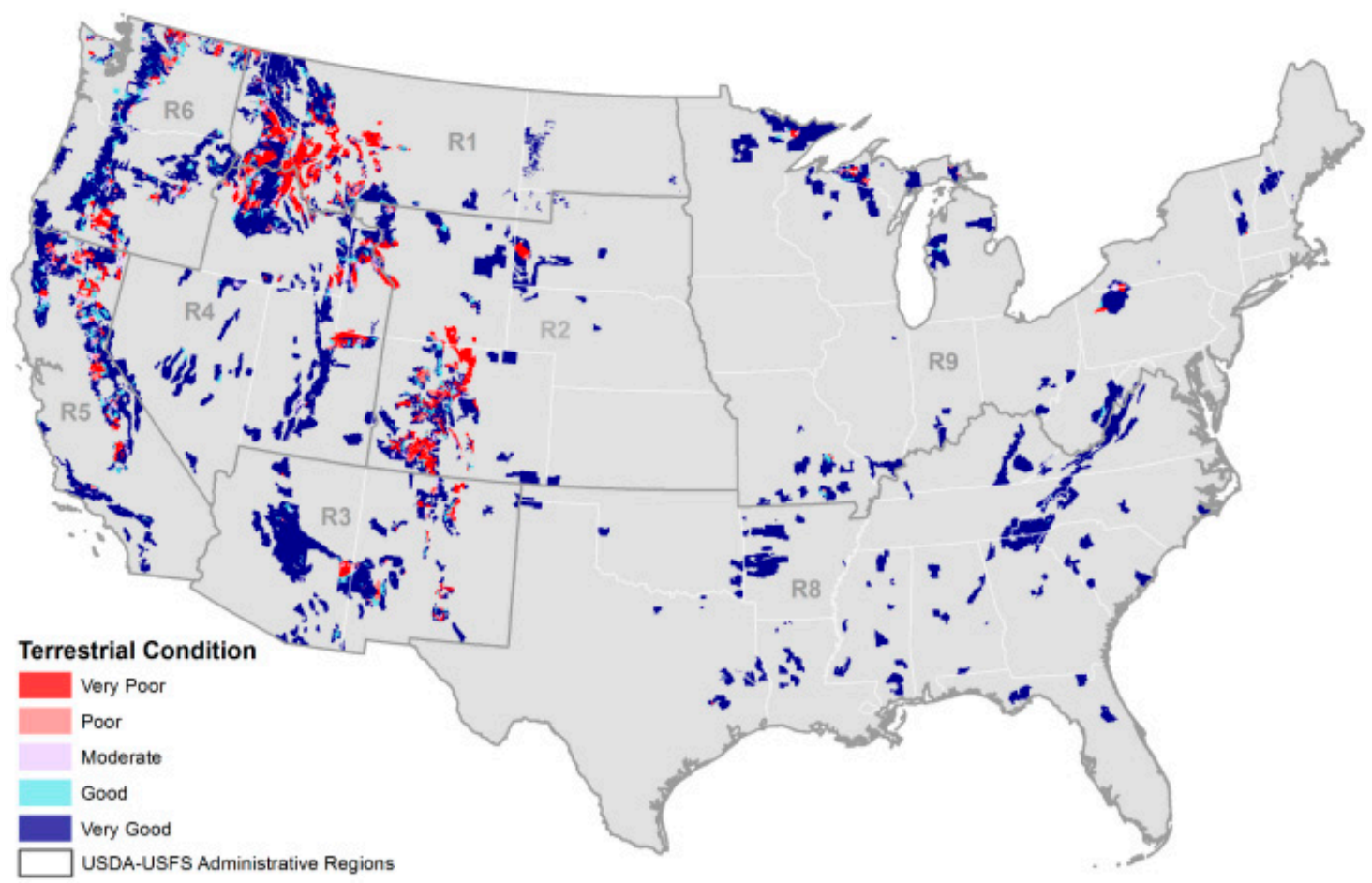

Figure 5. Ratings of the uncharacteristic tree mortality metric of the LTAs from the Terrestrial Condition Assessment on USDA Forest Service lands. Tree mortality is based on 2010-2015 surveys of current mortality and excessive defoliation due to insect and disease outbreaks. 


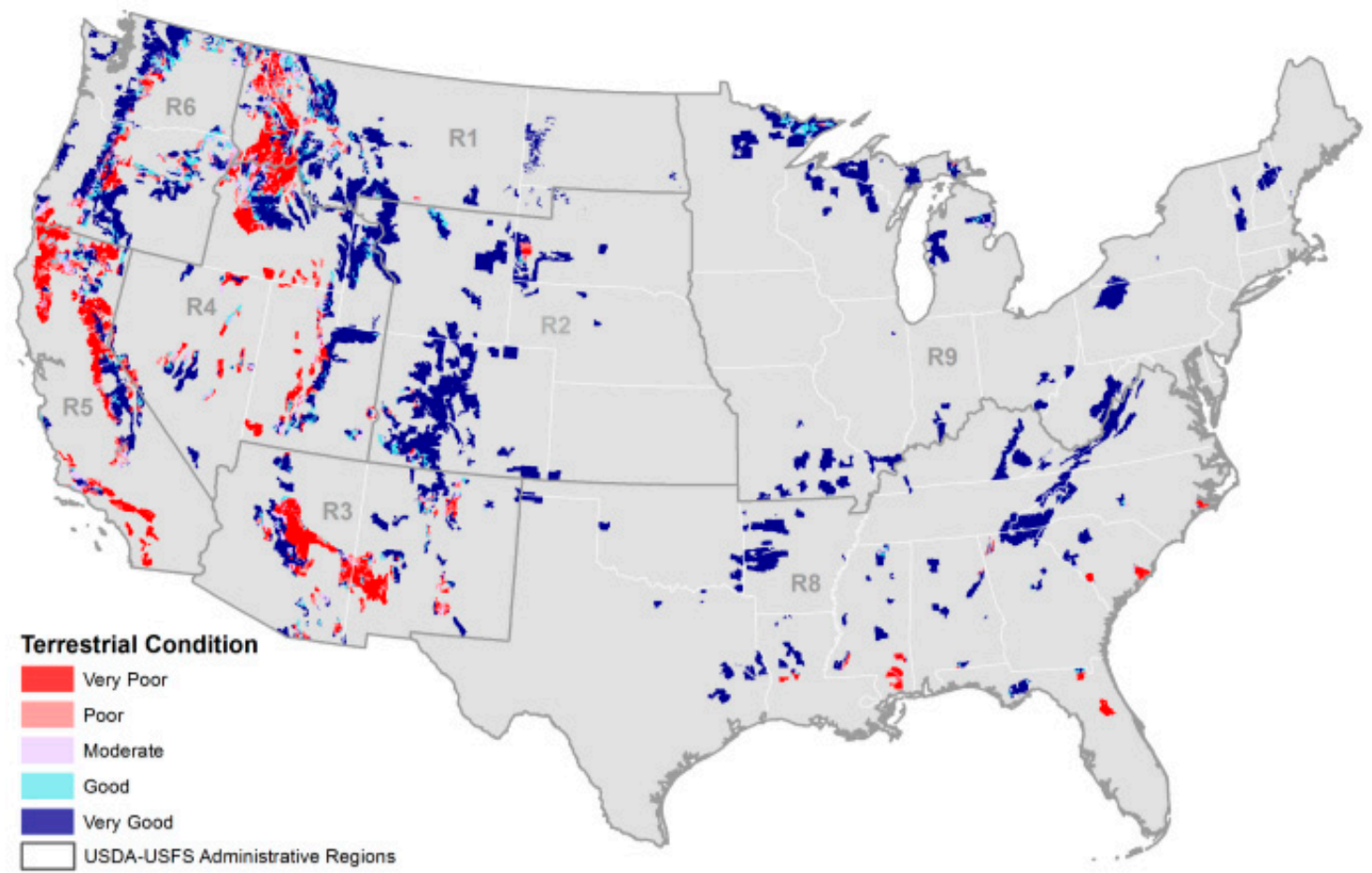

Figure 6. Ratings of the high and very high wildfire potential hazard metric of the LTAs from the Terrestrial Condition Assessment on USDA Forest Service lands.

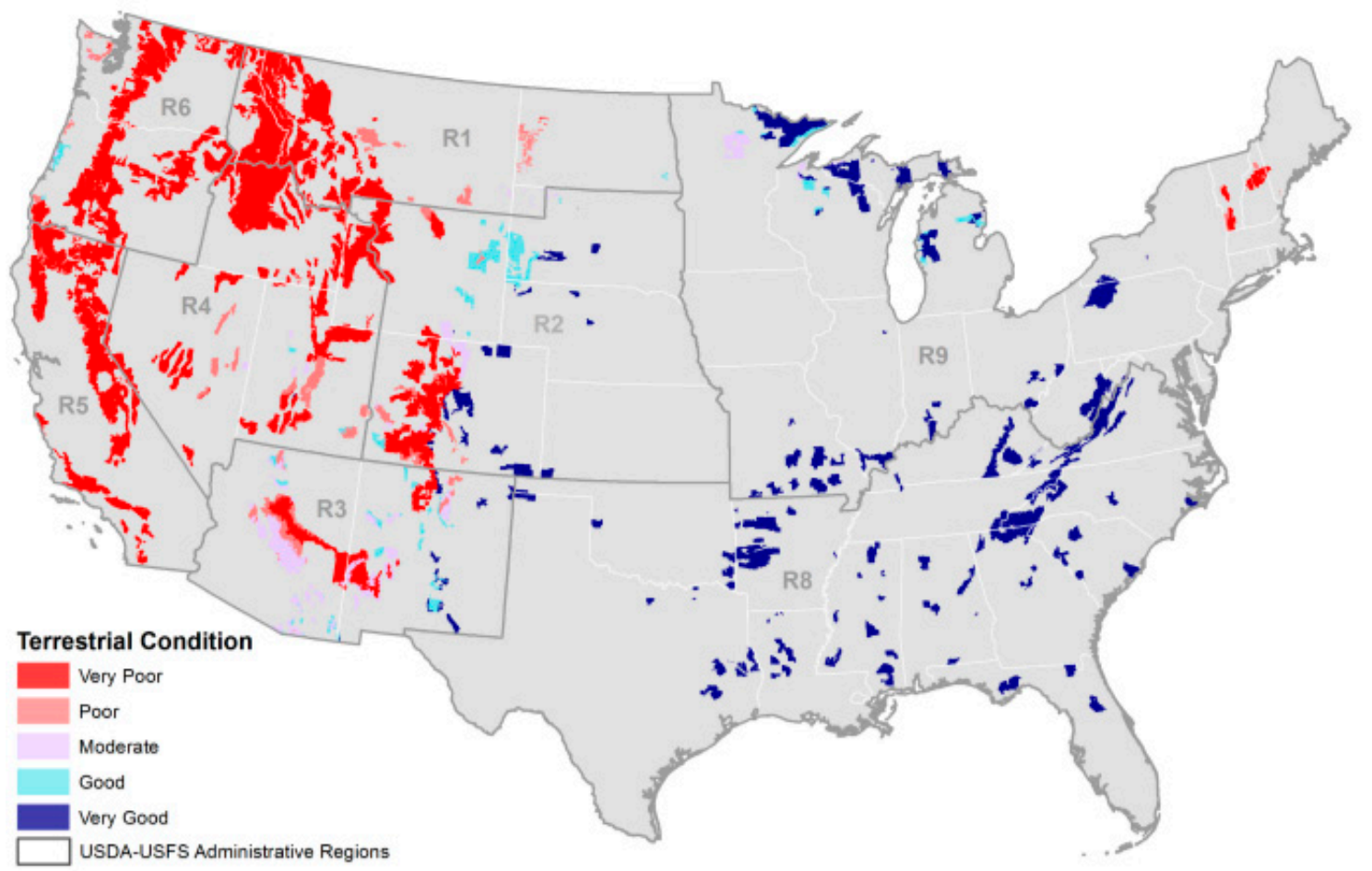

Figure 7. Ratings of the winter temperature shift metric of the LTAs from the Terrestrial Condition Assessment on USDA Forest Service lands. 


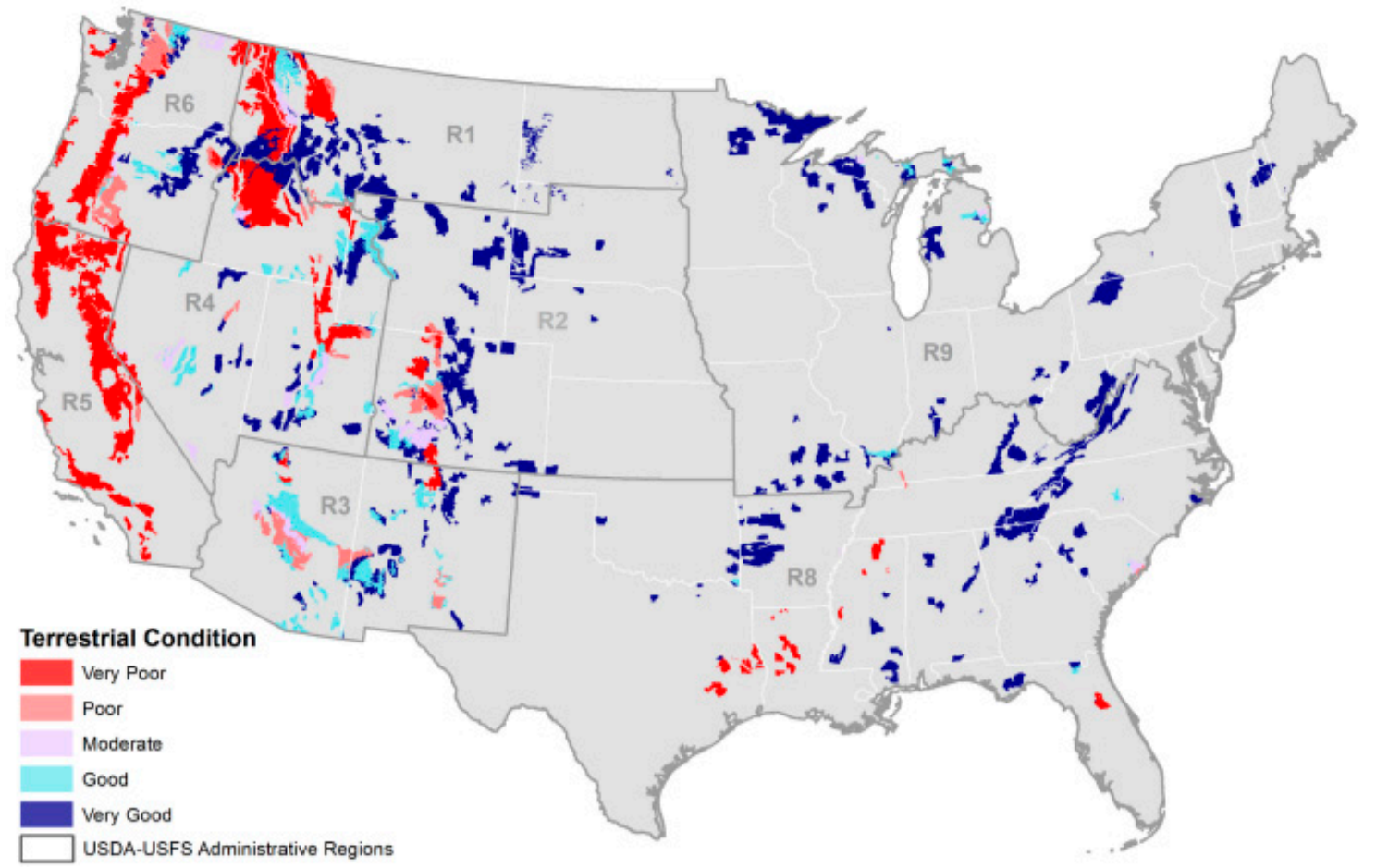

Figure 8. Ratings of the winter precipitation shift metric of the LTAs from the Terrestrial Condition Assessment on USDA Forest Service lands.

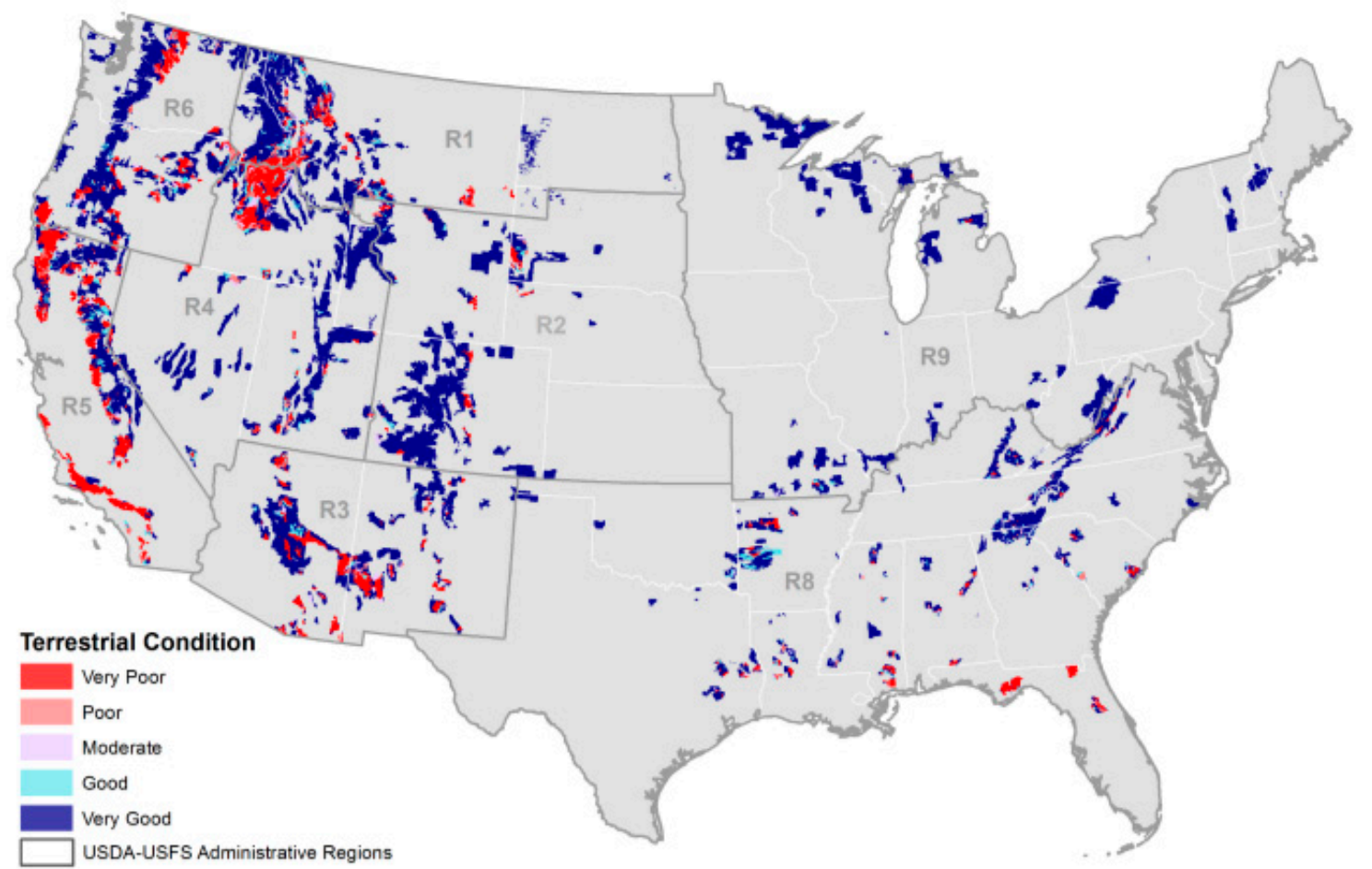

Figure 9. Ratings of the uncharacteristic wildfire indicator of the LTAs from the Terrestrial Condition Assessment on USDA Forest Service lands. 


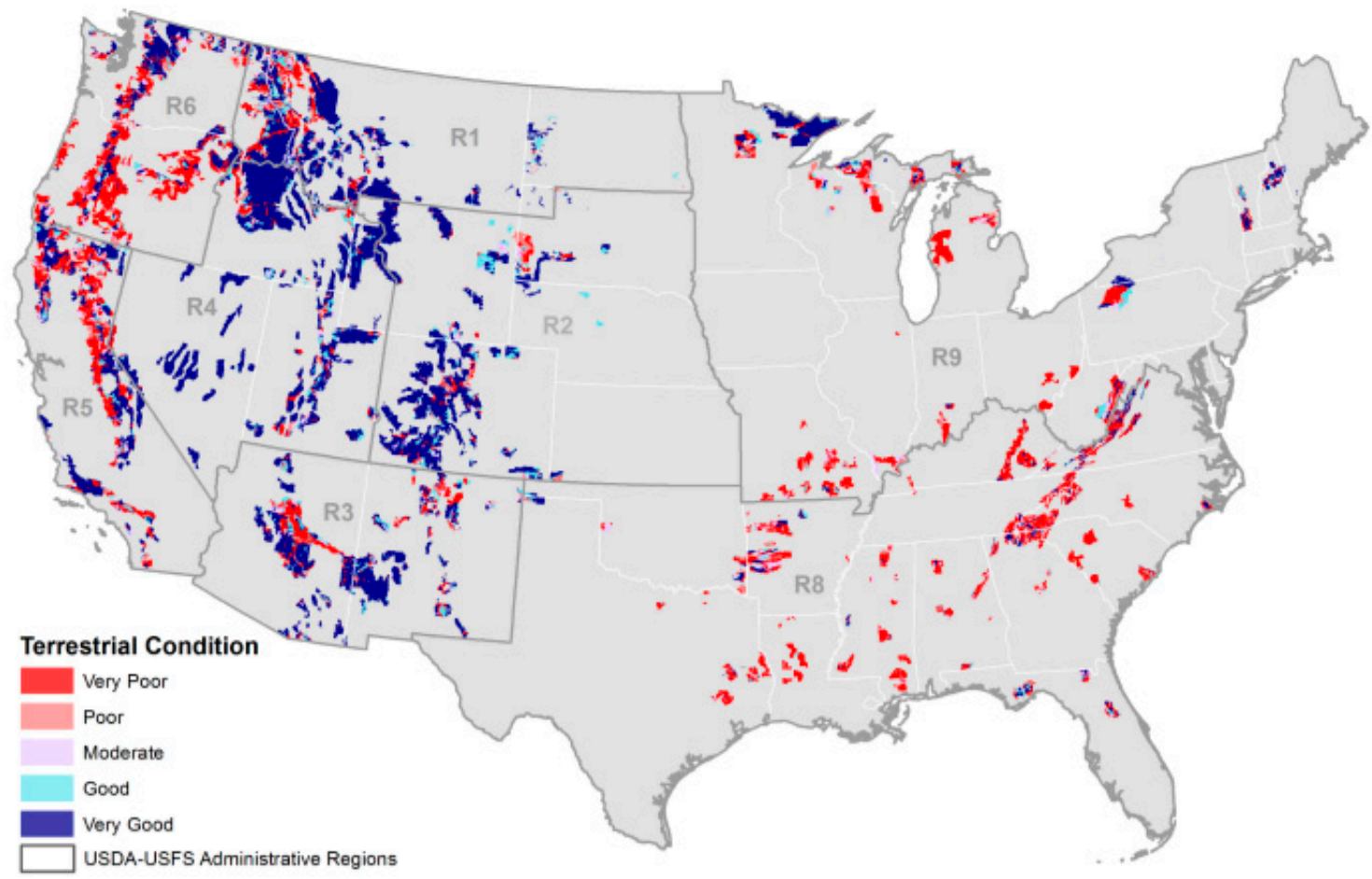

Figure 10. Ratings of the total road density metric of the LTAs from the Terrestrial Condition Assessment on USDA Forest Service lands.

In general, conditions in the eastern United States are better than much of the west, largely because of low fire hazard potential and very limited extent of current mortality. The primary stressors affecting National Forests in the east include high road densities (Figure 10), air pollution (Figure 11), and vegetation departure from reference conditions (Figure 12). National Forests in the southeast are also being impacted by uncharacteristically severe or frequent fires and reduced spring and fall precipitation.

Poor and very poor conditions are concentrated in the western United States. Of the 64.8 million hectares occurring within western national forests' proclamation boundaries, 20 percent or 13.1 million hectares are at imminent risk of uncharacteristic mortality due to insects and disease, 9.4 percent or 6.3 million hectares have experienced mortality in the past five years, and 33 percent or 21.2 million hectares have high or very high wildfire hazard potential. Stressors of uncharacteristically severe wildfire and climate exposure (elevated temperatures, particularly winter temperatures, and reduced precipitation) are severe in the west but almost nonexistent in the east.

At a regional scale (see Figure 1 for boundaries of the USFS regions), Regions 1, 2, 5, and 6 have very large percentages of very poor and poor conditions (Table 4). Region 1 has extensive areas with high insect and disease risk ( $37 \%$ of the Region), high and very high wildfire potential ( $34 \%$ of the Region), and high mortality occurring within the past five years (16\% of the Region). Region 2 has extensive areas with high insect and disease risk (20\% of the Region) and high recent mortality ( $13.4 \%$ of the Region). Region 5 has extensive areas with high and very high wildlife potential (53\% of the Region), high insect and disease risk ( $18 \%$ of the Region), high recent mortality ( $8.3 \%$ of the Region), and high road densities. Region 6 has high insect and disease risk (23\% of the Region). All western Regions are experiencing stress due to elevated temperatures and to a lesser degree reduced precipitation. Of greatest concern are increases in winter temperature (Figure 7) and decreases in winter precipitation (Figure 8). 


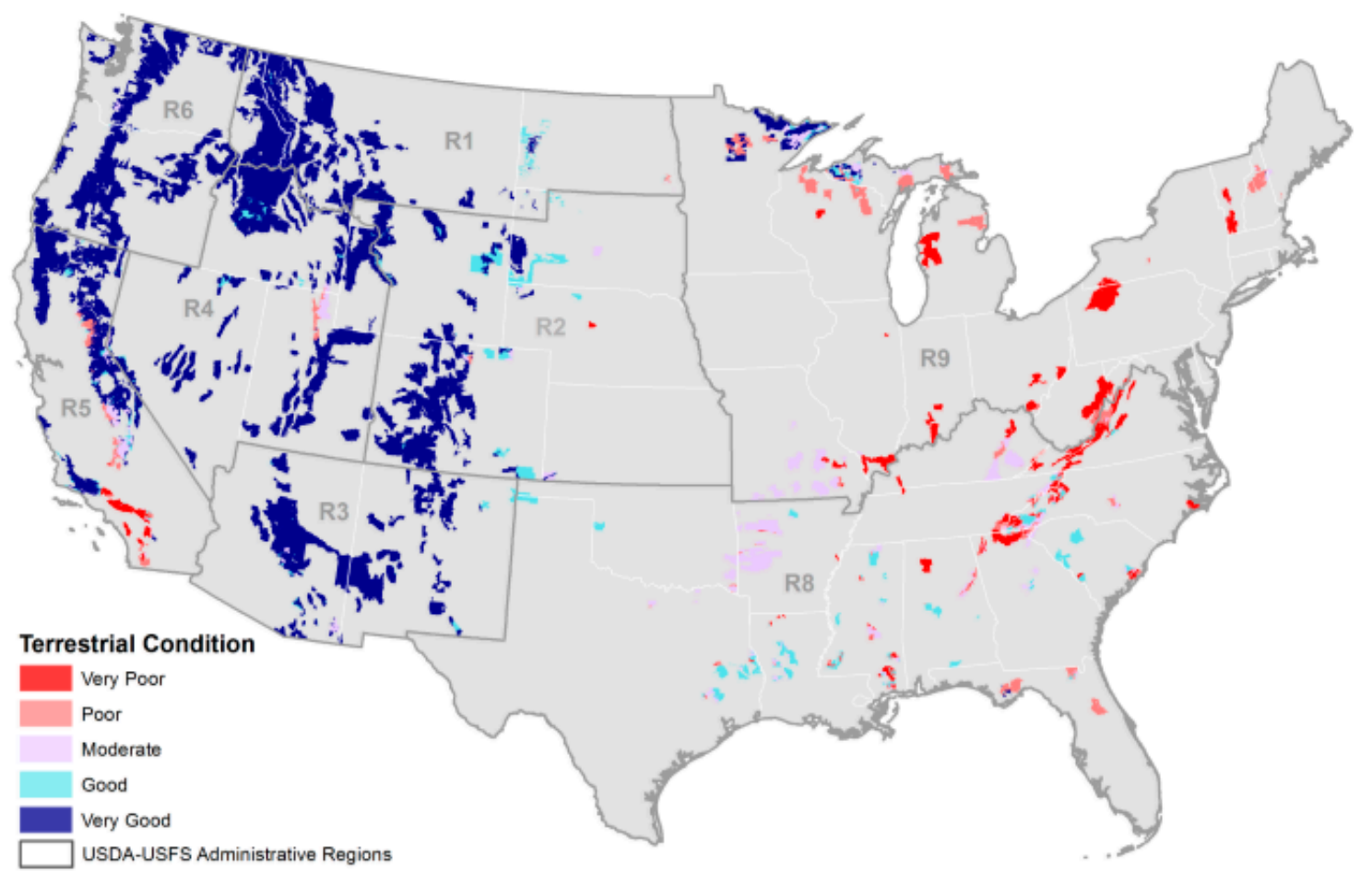

Figure 11. Ratings of the air pollution indicator of the LTAs from the Terrestrial Condition Assessment on USDA Forest Service lands.

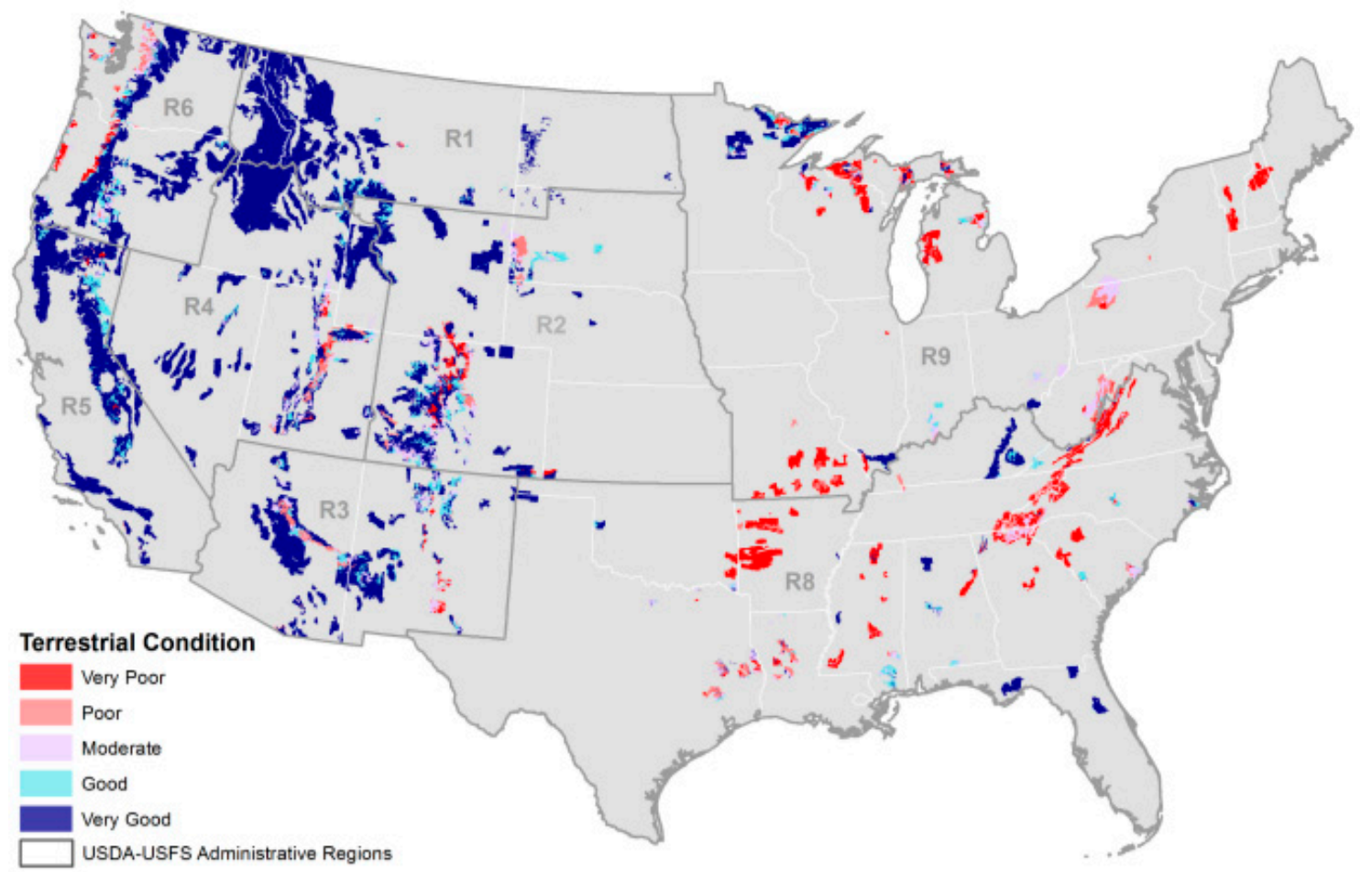

Figure 12. Ratings of the vegetation departure metric of the LTAs from the Terrestrial Condition Assessment on USDA Forest Service lands. 
Table 4. Frequency and areal distributions of the LTAs among the five overall ecological integrity ratings at the regional scale.

\begin{tabular}{cccccccc}
\hline Region & $\begin{array}{c}\text { Terrestrial } \\
\text { Condition }\end{array}$ & Hectares & $\begin{array}{c}\text { Percent } \\
\text { Regional }\end{array}$ & Region & $\begin{array}{c}\text { Terrestrial } \\
\text { Condition }\end{array}$ & Hectares & $\begin{array}{c}\text { Percent } \\
\text { Regional }\end{array}$ \\
\hline 1 & Very Good & $1,065,169$ & 9.46 & 5 & Very Good & 448,620 & 4.74 \\
1 & Good & $2,547,906$ & 22.62 & 5 & Good & $1,894,951$ & 20.01 \\
1 & Moderate & $1,711,470$ & 15.20 & 5 & Moderate & $3,263,593$ & 34.46 \\
1 & Poor & $1,497,393$ & 13.30 & 5 & Poor & $2,162,259$ & 22.83 \\
1 & Very Poor & $4,439,859$ & 39.42 & 5 & Very Poor & $1,702,486$ & 17.97 \\
\hline 2 & Very Good & $3,540,636$ & 31.51 & 6 & Very Good & $2,295,182$ & 20.36 \\
2 & Good & $3,213,151$ & 28.60 & 6 & Good & $2,573,660$ & 22.83 \\
2 & Moderate & $1,157,275$ & 10.30 & 6 & Moderate & $2,514,413$ & 22.30 \\
2 & Poor & 874,659 & 7.79 & 6 & Poor & $2,337,587$ & 20.73 \\
2 & Very Poor & $2,449,247$ & 21.80 & 6 & Very Poor & $1,554,411$ & 13.79 \\
\hline 3 & Very Good & $1,838,627$ & 19.76 & 8 & Very Good & 550,467 & 5.36 \\
3 & Good & $3,777,133$ & 40.59 & 8 & Good & $6,794,328$ & 66.13 \\
3 & Moderate & $2,236,714$ & 24.03 & 8 & Moderate & $1,860,729$ & 18.11 \\
3 & Poor & 834,357 & 8.97 & 8 & Poor & $1,060,174$ & 10.32 \\
3 & Very Poor & 619,630 & 6.66 & 8 & Very Poor & 8379 & 0.08 \\
\hline 4 & Very Good & $2,805,318$ & 20.08 & 9 & Very Good & $3,318,101$ & 35.44 \\
4 & Good & $6,056,478$ & 43.35 & 9 & Good & $5,038,891$ & 53.82 \\
4 & Moderate & $2,741,347$ & 19.62 & 9 & Moderate & 456,939 & 4.88 \\
4 & Poor & 634,118 & 4.54 & 9 & Poor & 385,028 & 4.11 \\
4 & Very Poor & $1,732,351$ & 12.40 & 9 & Very Poor & 163,139 & 1.74 \\
\hline
\end{tabular}

\section{Discussion}

Our results show a marked contrast between the eastern and western U.S., especially with respect to climate differences. The western United States has been subject to uncharacteristically severe wildfire in past decades largely due to a century of fire suppression, past logging, and climate exposure [28]. Fire suppression has resulted in increased tree densities and associated moisture demand, and increased fuel loads relative to historical or pre-European settlement forest conditions [29]. Increased winter temperatures reduce snowpack and water storage [30], and also reduce cold-induced mortality of damaging insects and diseases [31]. Increased temperatures during the growing season reduces fuel moisture, aggravating conditions promoting uncharacteristic wildfire [1,2], and increases the extent to which trees are stressed and less able to resist adverse effects of insect and disease.

Recent shifts in temperature affect western national forests far more than those in the east. The TCA used an increase of $1.11{ }^{\circ} \mathrm{C}\left(2{ }^{\circ} \mathrm{F}\right)$ as a threshold to identify LTAs undergoing recent severe temperature stress. Based on that threshold, $48 \%$ of NFS lands in the west are experiencing severe winter temperature stress in contrast to the less than one percent in the east. Spring, summer, and fall severe temperature stress affected $6.8 \%, 27.1 \%$, and $24.8 \%$ of western national forests, respectively. Conversely, spring, summer, and fall severe temperature stress affected less than one percent of eastern national forests. Interactions leading to poor conditions, including altered landscape patterns, fuel complexes, incidence of insect and disease caused mortality, and climate-induced stress, are therefore manifest in the western United States far more so than the east.

We have presented the TCA framework used to complete a national level assessment of ecological integrity based on uncharacteristic stressors, conditions, and disturbance agents for national forest system lands in the United States. Results, data, and guidance on analytical procedures have been produced for agency applications, including a web map viewer and web-based information delivery system. Applications for performance accounting are being developed at a national scale. Regional applications that include use of the TCA in addition to regional data and assessments are being initiated. Local applications in land management planning are taking place on select national forests involved in the planning revision process. Moving beyond a national product to support regional and local applications of the TCA is one of the next phases of the project. 


\subsection{Customizing TCA for NFS Regions and National Forests}

As mentioned in Section 2.5, the TCA assessment for the continental U.S. was intended as a starting point or template from which USFS Regions and National Forests could customize the assessment to make it more relevant to their local contexts. Customization of the analysis presented here can be done in at least four distinct ways:

1. National data presented in this study could be replaced with local data sources if local data sources were believed to be more accurate or more appropriate for the local context.

2. Thresholds used to define fuzzy membership functions that interpret the TCA metrics (Table 2) could be revised to better reflect local conditions. A good example in this context is the interpretation of road densities with respect to their effects on wildlife habitat fragmentation.

3. The national TCA logic includes several metrics related to uncharacteristic disturbances (indicator 6, Figure 2) including the spatial extent of mine impacts, landslides, blowdown, and flooding. Although logic topics and metrics associated with these impacts were designed into the NetWeaver logic model, they are turned off in the national analysis that we have presented because national data for these effects are not available. However, regions and forests could turn on one or more of these logic topics to include in their local assessments if they were considered important. Within the national TCA template, Region and Forest staff have two options for accounting for these ecosystem impacts: use of continuous measures (e.g., measured spatial extent) or use of ordinal rankings provided by specialists (see the HTML NetWeaver logic documentation included in the supplementary materials at the end of the paper).

4. Finally, the basic logic structure of the national TCA template is easily edited in NetWeaver by Region and Forest staffs to customize the logic for local contexts. For example, some logic topics in the national TCA template may not be considered relevant in some local contexts, in which case they can be turned off. In addition, the combination of logic operations used to synthesize evidence for logical premises of a particular logic topic might be edited by changing logic operators, or reorganizing the logic structure of premises to alter how a set of premises contribute to the strength of evidence for their parent topic.

The ability to customize the national TCA template for local application as described above creates some tension between assessments conducted at the different spatial extents of national, Region, and Forest. On the one hand, the national template was intended to promote, as far as practicable, consistency in how TCA assessments are conducted across spatial extents. On the other hand, an excessive emphasis on consistency across spatial extents has the potential to seriously compromise the utility of assessment products at more local extents. As a result, the NFS may need to consider an explicit governance process that balances the competing interests of national consistency and local relevance.

\subsection{Additional Steps in Decision Support for Ecosystem Restoration and Maintenance}

The results presented in this article evaluate the ecological integrity of LTAs on NFS lands in the continental US. However, in important respects, the analysis only represents the first step in a complete decision support process for the restoration of ecological integrity. In particular, the assessment characterizes terrestrial condition, which is an important foundation for a planning process, but it does not provide explicit support for implementing strategic and tactical planning decisions needed to meet restoration goals of the agency. As we discussed in Section 2.3, the EMDS framework includes a collection of decision engines that provide additional support for strategic and tactical decisions. In this section, we discuss how the associated decision support systems can be brought to bear to support management decisions for restoration and maintenance of LTAs.

The decision engine of CDP has been used for design of strategic multi-criteria decision models in EMDS since 2002 [15]. Whereas NetWeaver solutions describe the state of the system, strategic decision models assist resource managers with identifying which landscape units that are a high priority for 
management actions, by not only considering the state of the system, but by accounting for logistical considerations that are of practical importance to managers. Logistical considerations include such issues as feasibility, efficacy, cost, performance, consequences, social acceptability, etc., of potential management actions.

Whereas strategic decision models address the question of which landscape units are the highest priority for management, tactical decision models address the question of which management actions are the highest priority for any particular landscape unit, considering the biophysical context (or other contextual information) of the landscape unit. In other words, the strategic question concerns where, while the tactical question concerns what. Reynolds et al. [32] recently experimented with a CDP solution for tactical planning, however we believe that tactical decision models based on GeNIe and VisiRule may be more effective in tactical decisions, primarily because these systems can model more complex problems than CDP. For example, GeNIe supports sophisticated probabilistic reasoning based on Bayesian inference [33], and VisiRule, although providing a simple graphic interface, is supported by a powerful Prolog engine that allows very complex reasoning.

Reynolds et al. [32] also illustrated a variety of analytical sequences for decision support involving assessment and strategic and tactical planning, but more generally the architecture of EMDS was extensively re-engineered at version 5.0 to support the concept of workflows, by which any of the EMDS analytical components described above can be invoked in any sequence(s) (or series of sequences) needed to support spatial analysis and planning. EMDS currently supports Microsoft Windows Workflow for creating, running, and monitoring scientific workflows and Workflow NET. Interoperability of components is realized by data sharing, by which upstream analytical products are shared with any downstream analytical steps in an analysis sequence. In order to further extend interoperability in the workflow environment, EMDS now also implements Java script, R, and Python languages as tools for spatial data transformation.

\section{Conclusions}

The USDA Forest Service has recently completed an assessment of the ecological integrity of landscape ecosystems (LTAs) across its land base using the TCA framework. Results are beginning to be applied in national, regional, and local resource planning and management activities. Prospects for improving national performance accounting, and for developing strategic and tactical decision support systems that include social and economic considerations are being evaluated.

Supplementary Materials: The following are available online at 1. TCA metadata for data inputs to logic model https:/ / www.cloudvault.usda.gov/index.php/s/5YHcvq213tFZQ3D; 2. Complete documentation of the NetWeaver logic in HTML https:/ / www.cloudvault.usda.gov/index.php/s/rsHuooVYIk2xJLE; 3. ArcMap document with maps of all NetWeaver outputs for the TCA project https:/ / www.cloudvault.usda.gov/index. php/s/11u5oCMxGvYAlhq.

Acknowledgments: This study was funded by the National Forest System Washington Office of the US Department of Agriculture, Forest Service, including funds for covering the costs to publish in open access.

Author Contributions: All authors participated in the design and implementation of the TCA application; David Cleland and Robert Vaughan analyzed the data; Robert Vaughan did the geoprocessing to prepare data for EMDS; Keith Reynolds designed the NetWeaver logic and ran the analysis in EMDS; David Cleland, Barbara Schrader, and Larry Laing provided overall project oversight; David Cleland, Keith Reynolds, and Harbin Li wrote the paper.

Conflicts of Interest: The authors declare no conflict of interest.

\section{References}

1. Abatzoglou, J.T.; Willimas, P.A. Impact of anthropogenic climate change on wildfire across western US forests. Proc. Natl. Acad. Sci. USA 2016, 113, 11770-11775. [CrossRef] [PubMed]

2. Westerling, A.L.R. Increasing western US forest wildfire activity: Sensitivity to changes in the timing of spring. Philos. Trans. R. Soc. B 2016, 371, 20150178. [CrossRef] [PubMed] 
3. Six, D.L.; Biber, E.; Long, E. Management for Mountain Pine Beetle Outbreak Suppression: Does Relevant Science Support Current Policy? Forests 2014, 5, 103-133. [CrossRef]

4. FSM 2020: Ecological Restoration. Available online: https://www.fs.fed.us/dirindexhome/fsm/2000/wo_ 2020-2016-1.docx (accessed on 20 November 2017).

5. Potyondy, J.P.; Geir, T.W. Watershed Condition Classification Technical Guide; FS-978; USDA Forest Service: Washington, DC, USA, 2011.

6. Karr, J.R.; Dudley, D.R. Ecological perspective on water quality goals. Environ. Manag. 1981, 5, 55-68. [CrossRef]

7. Andreasen, J.K.; O’Neill, R.V.; Noss, R.; Slosser, N.C. Considerations for the development of a terrestrial index of ecological interity. Ecol. Indic. 2001, 1, 21-35. [CrossRef]

8. Ervin, J. Protected area assessments in perspective. BioScience 2003, 53, 819-822. [CrossRef]

9. Timko, J.A.; Innes, J.L. Evaluating Ecological Integrity in National Parks: Case Studies in Canada and South Africa. Biol. Conserv. 2009, 142, 676-688. [CrossRef]

10. Parrish, J.D.; Braun, D.P.; Unnasch, R.S. Are We Conserving What We Say We Are? Measuring Ecological Integrity within Protected Areas. BioScience 2003, 53, 851-860. [CrossRef]

11. Heckmann, K.E.; Manley, P.N.; Schlesinger, M.D. Ecological integrity of remnant montane forests along an urban gradient in the Sierra Nevada Forest. Ecol. Manag. 2008, 255, 2453-2466. [CrossRef]

12. Unnasch, R.S.; Braun, D.P.; Comer, P.J.; Eckert, G.E. The Ecological Integrity Assessment Framework: A Framework for Assessing the Ecological Integrity of Biological and Ecological Resources of the National Park System. Report to the National Park Service. 2008. Available online: http:/ / www.natureserve.org/sites / default/files/publications/files/nps_ecological_integrity_framework.pdf (accessed on 1 November 2017).

13. Cleland, D.T.; Avers, P.E.; McNab, W.H.; Jensen, M.E.; Bailey, R.G.; King, T.; Russell, W.E. National hierarchical framework of ecological units. In Ecosystem Management: Applications for Sustainable Forest and Wildlife Resources; Boyce, M.S., Haney, A., Eds.; Yale University Press: New Haven, CT, USA, 1997; pp. 181-200.

14. Thrush, S.F.; Hewitt, J.E.; Dayton, P.K.; Coco, G.; Lohrer, A.M.; Norkko, A.; Norkko, J.; Chiantore, M. Forecasting the limits of resilience: Integrating empirical research with theory. Proc. R. Soc. B 2009, 276, 3209-3217. [CrossRef] [PubMed]

15. Reynolds, K.M.; Rodriguez, S.; Bevans, K. User Guide for the Ecosystem Management Decision Support System, Version 3.0; Environmental Systems Research Institute: Redlands, CA, USA, 2003; 89p.

16. Reynolds, K.M.; Hessburg, P.F.; Bourgeron, P.S. (Eds.) Making Transparent Environmental Management Decisions: Applications of the Ecosystem Management Decision Support System; Springer: Berlin, Germany, 2014.

17. Ecosystem Management Decision Support System. Available online: https://en.wikipedia.org/wiki/ Ecosystem_Management_Decision_Support (accessed on 20 August 2017).

18. QGIS. Available online: http:/ / qgis.org/en/site/ (accessed on 20 August 2017).

19. MapWindow. Available online: http://www.mapwindow.org/ (accessed 20 August 2017).

20. Miller, B.J.; Saunders, M.C. The NetWeaver Reference Manual; Pennsylvania State University: College Park, PA, USA, 2002; p. 55.

21. Saaty, T.L. Multicriteria Decision Making: The Analytical Hierarchy Process; RWS Publications: Pittsburgh, PA, USA, 1992; p. 321.

22. Saaty, T.L. Fundamentals of Decision Making and Priority Theory with the Analytical Hierarchy Process; RWS Publications: Pittsburgh, PA, USA, 1994; p. 527.

23. Krist, F.J.; Ellenwood, J.R.; Woods, M.E.; McMahan, A.J.; Cowardin, J.P.; Ryerson, D.E.; Sapio, F.; Zweifler, M.O.; Romero, S.A. 2013-2017 National Insect and Disease Forest Risk Assessment. Available online: https:/ / www.fs.fed.us/foresthealth/technology/pdfs/2012_RiskMap_Report_web.pdf (accessed on 1 November 2017).

24. Zadeh, L.A. The concept of a linguistic variable and its application to approximate reasoning. Part I. Inf. Sci. 1975, 8, 199-249. [CrossRef]

25. Zadeh, L.A. The concept of a linguistic variable and its application to approximate reasoning. Part II. Inf. Sci. 1975, 8, 301-357. [CrossRef]

26. Zadeh, L.A. The concept of a linguistic variable and its application to approximate reasoning. Part III. Inf. Sci. 1976, 9, 43-80. [CrossRef]

27. von zur Gathen, J.; Gerhard, J. Modern Computer Algebra; Cambridge University Press: Cambridge, UK, 2003; p. 787. 
28. Collins, B.M.; Everett, R.G.; Stephens, S.L. Impacts of fire exclusion and recent managed fire on forest structure in old growth Sierra Nevada mixed-conifer forests. Ecosphere 2011, 2, 1-14. [CrossRef]

29. Naficy, C.; Sala, A.; Keeling, E.G.; Graham, J.; DeLuca, T.H. Interactive effects of historical logging and fire exclusion on ponderosa pine forest structure in the northern Rockies. Ecol. Appl. 2010, 20, 1851-1864. [CrossRef] [PubMed]

30. Margulis, S.A.; Cortes, G.; Girotto, M.; Huning, L.S.; Dongyue, L.; Durand, M. Characterizing the extreme 2015 snowpack deficit in the Sierra Nevada (USA) and the implications for drought recovery. Geophys. Res. Lett. 2016, 43, 6341-6349. [CrossRef]

31. Bentz, B.J.; Regniere, J.; Fettig, C.J.; Hansen, E.M.; Hayes, J.L.; Hicke, J.A.; Kelsey, R.G.; Negron, J.F.; Seybold, S.J. Climate change and bark beetles of the western United States and Canada: Direct and indirect effects. Bioscience 2010, 60, 602-613. [CrossRef]

32. Reynolds, K.M.; Murphy, P.J.; Paplanus, S. Toward geodesign for watershed restoration on the Fremont-Winema National Forest, Pacific Northwest, USA. Sustainability 2017, 9, 678. [CrossRef]

33. Henrion, M.; Breese, J.S.; Horvitz, E.J. Decision analysis and expert systems. AI Mag. 1991, 12, 64-91.

(C) 2017 by the authors. Licensee MDPI, Basel, Switzerland. This article is an open access article distributed under the terms and conditions of the Creative Commons Attribution (CC BY) license (http://creativecommons.org/licenses/by/4.0/). 